\title{
A systematic integrative review of the literature on midwives and student midwives engaged in problematic substance use
}

\begin{abstract}
Objective

The objective of this systematic integrative review was to review the literature in relation to problematic substance use (PSU) in midwifery populations. Associated aims were to aggregate existing knowledge about midwives and student midwives' personal engagement in PSU, to generate a holistic conceptualisation and synthesis of existing literature regarding midwives and student midwives personally engaged in PSU and to present new understandings and perspectives to inform the development of future research questions. This review is the first of its kind.
\end{abstract}

Design

Systematic searches were conducted in CINAHL, Academic Search Complete, MEDLINE, PSYCInfo, Scopus and the Cochrane Library. Findings were grouped into themes and subthemes relating to both midwives and student midwives and then analysed critically in relation to the wider literature. A quality assessment was conducted using the Mixed Methods Appraisal Tool (MMAT). The PRISMA statement was used to guide reporting.

Setting

Included studies were conducted in Scotland, Ireland, Australia and New Zealand.

Participants

Studies included a total of 6,182 participants.

Findings

A total of 3 studies were included. All included study types comprised quantitative survey designs, yet one also included a mixed methods design with the use of semi structured interviews. Two overarching themes emerged relating to both midwives and student midwives engaged in problematic substance use. For midwives, three subthemes are described: harmful daily alcohol consumption, working hours and harmful daily alcohol consumption and features associated with harmful daily alcohol consumption. For student midwives, two subthemes are presented: escape avoidance and alcohol, tobacco and cannabis use.

Key conclusions

There is limited evidence available in relation to problematic substance use in midwifery populations in comparison to that available for other healthcare populations. Further research is required and could usefully focus upon midwives and student midwives as distinct professions to be separated out from the wider healthcare workforce.

Implications for practice

Problematic substance use among the healthcare workforce is associated with an increase in medical errors and inadequate care. Those affected can be reluctant to seek help, experience psychological distress and even contemplate suicide. Whilst evidence remains lacking for midwifery populations, they form a part of the general healthcare workforce and are exposed to similar workplace stressors. As such, it is likely that they would be affected in similar ways.

\section{Keywords}


Impairment; Health Professional; Workplace Stress; Midwives; Substance Use: Alcohol; Integrative Review; Psychological Distress

\section{Introduction}

There is evidence to suggest that health professionals use substances to manage the stress and burnout which can result from working in health and social care (Monroe, T. B. et al., 2013). Historically, midwifery professionals have been described as being at particular risk of this (Roth, 1987), and in a recent nationwide survey conducted in the United Kingdom (UK), $83 \%$ of midwives reported burnout (Hunter et al., 2019). Moreover, in a recent sequential mixed methods analysis examining fitness to practise (FtP) cases occurring between 2014 and 2016, a number of those put before the Nursing and Midwifery Council (NMC) in particular related to alcohol $(n=208)$ and drug use $(n=131)$ (Searle et al., 2017). Such episodes of addiction, alcohol and drug use are classed as individual health concerns. Yet, whilst they can leave a variety of healthcare professionals depleted (Searle et al., 2017), and both workplace safety and the safety of care compromised (Servodidio, 2011), relevant literature has thus far been largely dominated by the experiences and care of physicians (Chen and Leung, 2019; Weenink et al., 2017). The objective of this systematic integrative review was to review the literature in relation to problematic substance use (PSU) in midwifery populations.

Some recent studies have focussed upon the experiences of nurses engaged in PSU (Mumba and Kraemer, 2019; Ross, Berry et al., 2018; Ross, Jakubec et al., 2018; Worley, 2017). Indeed, the topic of PSU among nurses has been explored since the time of Florence Nightingale (Montgomery-Dossey, 2009), and currently it is thought that PSU may be a concern for as many as $8-20 \%$ nursing professionals (Ross, Berry et al., 2018). Common findings within these works relate to a lack of support, fear, stigma, denial, unhealthy coping behaviours and the need for targeted workplace wellbeing interventions. It is suggested to be likely that such concerns are also an issue for a variety of healthcare professions, including the midwifery profession (Weenink et al., 2017). Yet an initial scoping of the literature indicated a paucity on the same topic with regards to midwifery populations. Given the proposal that professional misconduct and unsafe care might be detected through exploring and attending to the needs of professionals engaged in PSU (Searle et al., 2017), we assert that the limited quantity of scholarly inquiry strictly impairs the development of midwifery knowledge in this area.

\section{Aims}

1. To aggregate existing knowledge about midwives and student midwives' engagement in PSU.

2. To generate a holistic conceptualisation and synthesis of existing literature regarding PSU among midwives and student midwives.

3. To present new understandings and perspectives to inform the development of future research questions. 


\section{Methods}

\section{Study design}

Given the identified paucity of literature regarding PSU among midwifery professionals from an initial scoping exercise, we considered this to be an emerging topic area. Therefore, a systematic integrative review strategy was selected as this is considered appropriate and particularly apt for generating a preliminary conceptualization of the topic under investigation (Torraco, 2005). The PRISMA statement was used to guide reporting (Moher et al., 2009).

\section{Literature search}

As is customary for systematic integrative reviews, a comprehensive literature search was performed to broadly uncover existing evidence on the topic of midwives and student midwives engaged in PSU. Our search strategy replicates that used by Ross et al (2018), which was focused on nurses engaged in PSU, yet here, we focus on midwifery populations. Subject and mesh headings were used where available and were 'exploded' where possible. Full details on the search strategy are outlined in table 1. A total of 161 records were yielded via this stage. Following the removal of duplicate articles, the title and abstracts of those remaining were subsequently screened by the first author. Anecdotal testimonies, irrelevant and newsletter articles were excluded. Lastly, 6 full text articles were read in full and assessed for eligibility collectively by the research team. Final articles were included if they were written in English and offered any empirical evidence in relation to midwives and/or student midwives engaged in PSU. Upon conclusion of this process, three articles were identified for inclusion by the research team via a series of academic discussions. The reference lists of these were also screened by the lead author for further relevant articles, yet no further articles met the inclusion criteria. The processes for selecting articles are presented via a comprehensive PRISMA flow diagram in figure 1 (Moher et al., 2009).

Table 1: Search strategy

\begin{tabular}{|l|l|l|}
\hline \hline Database & Major Subject Headings & $\begin{array}{l}\text { Number of articles } \\
\text { retrieved }\end{array}$ \\
\hline CINAHL & $\begin{array}{l}\text { Midwi* AND (SU) impairment, health } \\
\text { professionals }\end{array}$ & 47 \\
\hline $\begin{array}{l}\text { Academic Search } \\
\text { Complete }\end{array}$ & $\begin{array}{l}\text { Midwi* AND (SU) "IMPAIRED medical } \\
\text { personnel" }\end{array}$ & 17 \\
\hline MEDLINE [Full Text] & Midwi* AND “Professional Impairment” & 12 \\
\hline PSYCInfo & Midwi* AND “impaired professionals" & 35 \\
\hline Scopus & midwi* AND professional AND impairment & 47 \\
\hline Cochrane Library & Midwi* AND “Professional Impairment” & 3 \\
\hline Total & & $\mathbf{1 6 1}$ \\
\hline
\end{tabular}


Figure 1: PRISMA flowchart processes for selecting articles
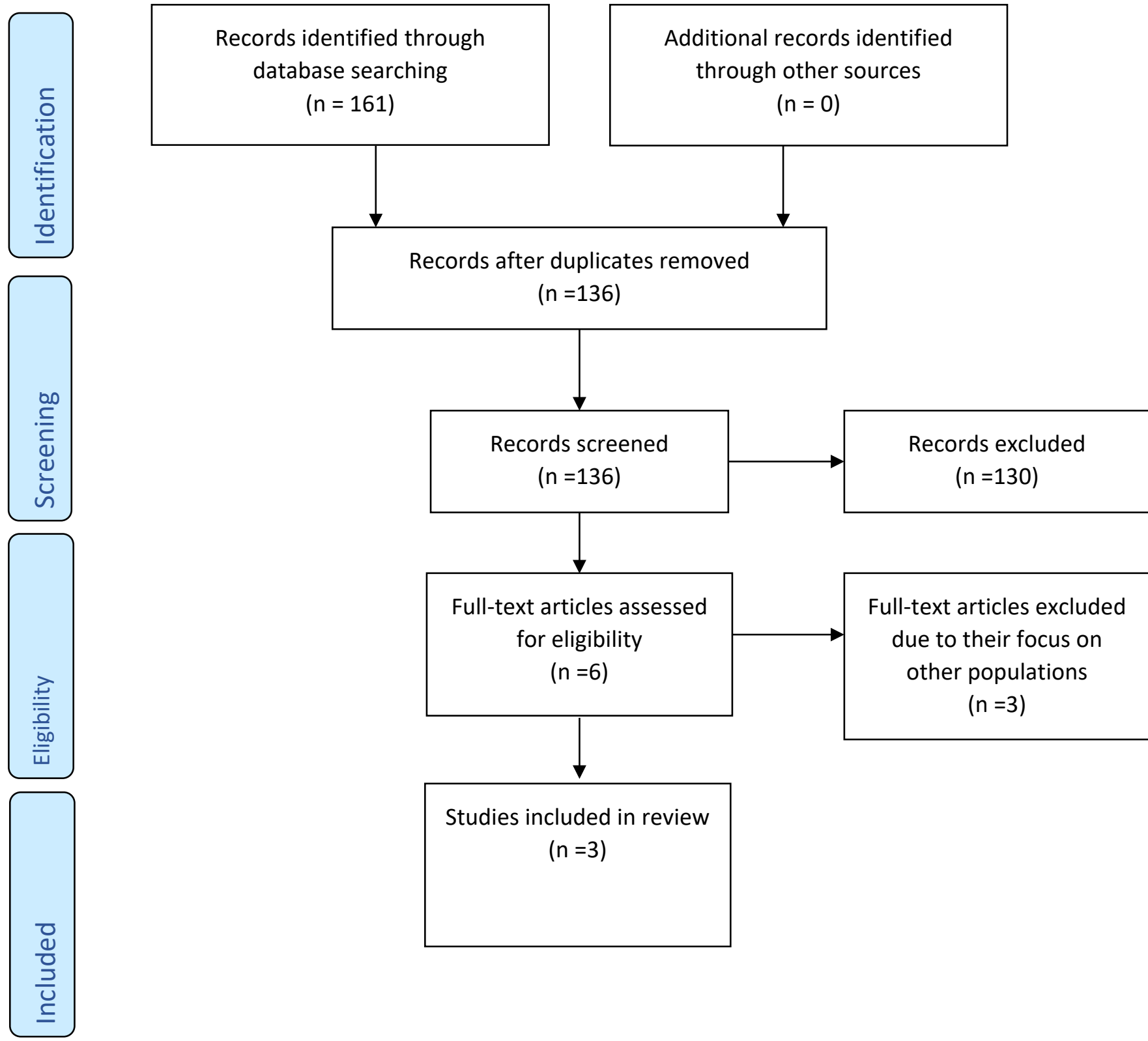

Studies included in review $(n=3)$ 
Assessment of study quality

The team engaged in a process of evaluation relating to the existing knowledge on midwives and student midwives engaged in PSU. This included a quality appraisal of each article using the Mixed Methods Appraisal Tool (MMAT), which enables researchers to evaluate the validity and reliability of both quantitative and qualitative empirical study designs simultaneously (Hong et al., 2018; Pluye et al., 2009). MMAT quality scores range from * if one criterion is met to $* * * * *$ if all five criterion are met (Pluye et al., 2009). An initial quality assessment was conducted by the first author. This was subsequently reviewed and agreed by the wider review team.

\section{Synthesis of findings}

Articles selected for inclusion were read in detail by the first author. Themes of relevance were highlighted and findings relating to midwives and student midwives engaged in PSU were differentiated through a succession of refinements in partnership with the wider research team. Due to the types of populations included within the three studies, findings in relation to midwives and student midwives demarcated the final two themes.

Under each of these final themes relating to either midwives or student midwives, subthemes in relation to problematic substance use were primarily aggregated under subheadings. Both themes and subthemes were then finalised in partnership with the wider team. Subsequently, these findings were critically analysed and presented as a discussion in order to synthesize a holistic conceptualization of the evidence. In line with our chosen methodology, this synthesis was rooted in a research agenda, adopting provocativeness to generate new ideas and directions for the field. The outcomes from this process of discovery are presented below.

\section{Results}

Figure 1 outlines how articles were selected for inclusion via a comprehensive PRISMA flow diagram (Moher et al., 2009). The three final studies selected for inclusion were carried out in Scotland (Watson et al., 2006), Ireland (Deasy et al., 2014) and Australia and New Zealand (Schluter et al., 2012). A total of 6,182 participants were included across these studies. In two of the three studies (Deasy et al., 2014; Schluter et al., 2012), samples were referred to collectively as nursing and midwifery professionals, thus specific numbers of midwives could not be identified. Of note, the sample from New Zealand $(n=867)$ were specifically identified as nurses, yet due to the complexity of data available to us, we have been unable to remove this data from our analyses entirely. The third study (Watson et al., 2006), identified 13 participants as midwifery students. Consequently, only 13 of the participants included were categorised as midwifery professionals. 
All study types included quantitative survey designs, while one also included a mixed methods design with the use of semi structured interviews (Deasy et al., 2014). Study overviews and characteristics are outlined in table 2.

Overall, two overarching themes emerged in relation to both midwives and student midwives. Table 3 displays these overarching themes and the subthemes that were identified within them. For midwives engaged in problematic substance use, three subthemes are described: harmful daily alcohol consumption, working hours and harmful daily alcohol consumption and features associated with harmful daily alcohol consumption. For student midwives engaged in problematic substance use, two subthemes are presented: escape avoidance and alcohol, tobacco and cannabis use. 
Table 2: Study overviews and characteristics

\begin{tabular}{|c|c|c|c|c|c|c|}
\hline Article & $\begin{array}{l}\text { Design and } \\
\text { methods }\end{array}$ & Participants & Geographical area & Data collection tools & Relevant findings & $\begin{array}{l}\text { Quality } \\
\text { Score }\end{array}$ \\
\hline $\begin{array}{l}\text { (Schluter et } \\
\text { al., 2012) }\end{array}$ & $\begin{array}{l}\text { Quantitative } \\
\text { cross- } \\
\text { sectional } \\
\text { survey }\end{array}$ & Nurses and Midwives ( $n=4419)$ & $\begin{array}{l}\text { Australia }(n=3552) \\
\text { New } \\
\text { (nurses } \\
\text { ( } n=867)\end{array}$ & $\begin{array}{l}\text { Food Frequency Questionnaire (FFQ) } \\
\text { 18-item version of the Job Content } \\
\text { Questionnaire (JCQ) } \\
\text { Hostility score 3-item self-report scale } \\
\text { SF-36 (version 2) }\end{array}$ & $\begin{array}{l}\text { Significant associations between } \\
\text { long working hours and harmful } \\
\text { daily alcohol consumption }\end{array}$ & $* * *$ \\
\hline $\begin{array}{l}\text { (Deasy et } \\
\text { al., 2014) }\end{array}$ & $\begin{array}{l}\text { Mixed } \\
\text { methods } \\
\text { study utilising } \\
\text { interviews } \\
\text { and a } \\
\text { quantitative } \\
\text { survey design }\end{array}$ & $\begin{array}{l}\begin{array}{l}\text { Undergraduate } \\
\text { students }(n=473)\end{array} \\
\text { Teacher education students }(n=1104)\end{array}$ & $\begin{array}{l}\text { A single university } \\
\text { in Ireland }\end{array}$ & $\begin{array}{l}\text { General Health Questionnaire (GHQ) } \\
\text { The Ways of Coping Questionnaire (WOC) } \\
\text { Lifestyle Behaviour Questionnaire } \\
\text { (LBQ) } \\
\text { Open and flexible interview schedule } \\
\text { informed by a critical analysis of the } \\
\text { literature }\end{array}$ & $\begin{array}{l}\text { Positive relationship between } \\
\text { elevated psychological distress, } \\
\text { coping and escape avoidance } \\
\text { behaviours including substance use } \\
\text { (alcohol, tobacco and cannabis) }\end{array}$ & $* * * *$ \\
\hline $\begin{array}{l}\text { (Watson et } \\
\text { al., 2006) }\end{array}$ & $\begin{array}{l}\text { Quantitative } \\
\text { survey design }\end{array}$ & $\begin{array}{l}186 \text { first year students in the fields of: } \\
\text {-Adult Nursing ( } n=88) 47.3 \% \\
\text {-Children's nursing ( } n=43) 23.1 \% \\
\text {-Mental health nursing }(n=34) 18.3 \% \\
\text {-Learning Disability Nursing }(n=8) 4.4 \% \\
\text {-Midwifery }(n=13) 7.0 \%\end{array}$ & $\begin{array}{l}\text { A single university } \\
\text { in Scotland }\end{array}$ & $\begin{array}{l}\text { European Health and Behaviour Survey } \\
\text { Questionnaire. }\end{array}$ & $\begin{array}{l}\text { Harmful levels of alcohol } \\
\text { consumption and rates of smoking } \\
\text { higher than national average }\end{array}$ & $* *$ \\
\hline
\end{tabular}


Table 3: Themes and subthemes

\begin{tabular}{|l|l|l|l|l|l|}
\hline \multirow{2}{*}{} & \multicolumn{4}{|l|}{$\begin{array}{l}\text { Student midwives engaged in } \\
\text { problematic substance use }\end{array}$} & \multicolumn{2}{l|}{$\begin{array}{l}\text { Midwives engaged in problematic substance } \\
\text { use }\end{array}$} \\
\cline { 2 - 6 } & $\begin{array}{l}\text { Escape } \\
\text { Avoidance }\end{array}$ & $\begin{array}{l}\text { Alcohol, } \\
\text { tobacco and } \\
\text { cannabis use }\end{array}$ & $\begin{array}{l}\text { Harmful } \\
\text { daily alcohol } \\
\text { consumption }\end{array}$ & $\begin{array}{l}\text { Working } \\
\text { hours and } \\
\text { harmful daily } \\
\text { alcohol } \\
\text { consumption }\end{array}$ & $\begin{array}{l}\text { Features } \\
\text { associated } \\
\text { with harmful } \\
\text { daily alcohol } \\
\text { consumption }\end{array}$ \\
\hline $\begin{array}{l}\text { (Schluter } \\
\text { et al., } \\
\text { 2012). }\end{array}$ & & & $v$ & $v$ & $v$ \\
\hline $\begin{array}{l}\text { (Deasy et } \\
\text { al., 2014). }\end{array}$ & v & $v$ & & & \\
\hline $\begin{array}{l}\text { (Watson } \\
\text { et al., } \\
\text { 2006) }\end{array}$ & & $v$ & & & \\
\hline
\end{tabular}

\section{Quality appraisal}

For their individual methodologies, all selected studies met at least two of the five quality criteria. None met all five. Limitations of the cross sectional study (Schluter et al., 2012), related to potential systematic response bias, low response rates, partial survey answers, and social desirability bias or deliberate under-reporting. The mixed-methods study conducted by Deasey et al. (2014), was somewhat limited by a single data collection site and the use of selfreport measures. The survey by Watson et al. (2006) was considered to be of lower quality due to its small sample size with data collected from a single site.

\section{Samples studied}

The study by Schluter et al., (2012) was the only one to include qualified midwives. The authors sought to investigate the relationship between work hours and alcohol problems in a large cohort of qualified nurses and midwives from Australia $(n=3352)$ and qualified nurses from New Zealand ( $n=867$ ). The authors assert that this sample of 4419 captured $2.3 \%$ of the contemporary workforce in Australian and New Zealand. Two selected studies included student midwifery populations (Deasy et al., 2014; Watson et al., 2006). In the survey conducted by Watson et al. (2006), 13 participants identified as student midwives. The authors of Deasy et al., (2014) report that 1112 students (86\% from nursing and $64 \%$ from education) completed their survey (response rate $71 \%$ ). It is not clear how many of these were midwifery students. 


\section{Data collected}

Schluter et al., (2012) in their quantitative study used validated tools such as: the Food Frequency Questionnaire (FFQ) (Willett et al., 1985); the 18-item version of the Job Content Questionnaire (JCQ) (Karasek et al., 1998); the hostility score 3-item self-report scale (Koskenvuo et al., 1988); and the SF-36 (version 2) (Ware et al., 2000); to assess working hours, alcohol consumption, alcohol dependency, Job stresses, co-worker and supervisor support, general physical and mental health attributes, along with functional health and wellbeing. Though data relating to participants' distinct employment and workplace setting was also assessed, findings in relation to both the nursing and midwifery professions are predominantly presented collectively.

The mixed method study by Deasy et al., (2014) applied: the General Health Questionnaire (GHQ) (Goldberg, 1981) to establish levels of self-reported psychological distress; the 'Ways of Coping' Questionnaire (WOC) (Folkman and Lazarus, 1988) to assess processes of coping; and the independently verified Lifestyle Behaviour Questionnaire (LBQ) to examine the lifestyle behaviours of 1557 undergraduate nursing/midwifery and teacher education students from a single university in Ireland. Individual interviews $(n=559)$ also provided new understandings in relation to student's experiences of psychological distress and coping (Deasy et al., 2014). Watson et al., (2006) apply the European Health and Behaviour Survey Questionnaire (Wardle and Steptoe, 1991) to measure the smoking and alcohol consumption of 186 first year nursing and midwifery students from a single university in Scotland.

\section{Theme One: Midwives Engaged in Problematic Substance Use}

This theme presents the various aspects associated with PSU amongst qualified midwives.

\section{Subtheme one: Harmful daily alcohol consumption}

In the study by Schluter et al. (2012), of the 4239 participants who responded to questions about daily alcohol consumption, 588 (13\%; 95\%Cl: $12.8 \%, 14.9 \%)$ consumed more than 2 standard drinks/day. Notably, of the 4336 participants who responded to the questions about alcohol dependency, 68 (1.6\%; 95\% Cl: 1.2\%,2.0\%) declared being diagnosed with an alcohol dependence problem. Of those who consumed more than 2 standard drinks/day, $13(0.3 \%)$ also had a diagnosis of alcohol dependence problem, whilst 571 (13.6\%) did not. Interestingly, of those indicating a diagnosis of alcohol dependency, 51 (1.2\%) consumed less than 2 standard drinks/day. Moreover, 3574 (84.9\%) of participants who consumed less than 2 standard drinks/day were not indicated with a diagnosis of alcohol dependency $(k=0.01)$.

The multivariable logistic regression analysis of standard daily drink consumption in females yielded a complete case OR of 1.65 (95\% Cl: 1.22, 2.23) and an imputed OR of 1.44 (95\% Cl: $1.12,1.87$ ) (Schluter et al., 2012). For male participants, this same analysis yielded a complete case OR of $2.90(95 \% \mathrm{Cl}: 1.93,4.37)$ and an imputed OR of $2.68(95 \% \mathrm{Cl}: 1.86,3.86)$. Note that data relating to midwives are not individualised in this study. 
Subtheme two: Working hours and harmful daily alcohol consumption

In the authors' crude and adjusted complete case and imputed logistic regression models, significant associations between long working hours and harmful daily alcohol consumption were noted (Schluter et al., 2012). Specifically, the odds of harmful daily drinking increased by 1.17 (95\% confidence interval: 1.01, 1.36) between those working less than $40 \mathrm{~h} /$ week and 40-49 h/week, and those working between 40-49 h/week and more than $50 \mathrm{~h} /$ week according to the authors' adjusted model with imputed data.

Subtheme three: Features associated with harmful daily alcohol consumption

Of the 3352 Australian nurses and midwives included, 512 (14.6\%) were also current smokers. These current smokers were found to have a higher odds ratio of drinking more than 2 standard drinks/day compared to non-smokers. Other subgroups found to have a higher odds ratio of drinking more than 2 standard drinks were those with lower SF-36 mental health component scores, males, and those with low strain or active job stress (Schluter et al., 2012).

\section{Theme two: Student Midwives Engaged in Problematic Substance Use}

This theme presents the various aspects associated with PSU amongst student midwives.

\section{Subtheme one: Escape avoidance}

Deasy et al., (2014) identified that overall, $41.9 \%$ of respondents were reportedly psychologically distressed. In order to cope, students sought social support, and engaged in problem solving and escape avoidance (through substance use, comfort eating, isolation and denial). Such escape avoidance was positively linked with elevated psychological distress. They also found a statistically significant relationship between diet and escape avoidance. In particular, those whose eating habits were influenced by mood, money, stress, worry, boredom or drinking alcohol also used escape avoidance frequently. Likewise, participants were found to use escape avoidance more frequently if they were also current tobacco smokers, recent users of cannabis, regular drinkers, or not particularly physically active. Nursing/midwifery students were found to cope via escape avoidance more frequently (mean score 8.45) than teacher education students (mean score 7.61) (Deasy et al., 2014).

Analysis of the individual interviews ( $n=59$ ) conducted by Deasy et al., (2014) revealed a recurrent theme of escape/avoidance. Participants engaged in substance use when they needed "something that is in some way liberating from what was going on at the time". Denial of stress was common, with participants attempting to "hide it from everyone", not wanting to admit vulnerability (Deasy et al., 2014).

\section{Subtheme two: Alcohol, tobacco and cannabis use}

In the survey conducted by Watson et al.,(2006) the level of substance use measured in the student population $(n=186)$ was also higher than the general population and problematic in some cases. Here, 51 (28\%) of participants were cigarette smokers. Additionally, 134 (74\%) reported drinking at levels that exceed the daily benchmarks for low risk drinking (2-3 units/day for women and 3-4 units/day for men, not exceeding 14 units/week with at least 
one alcohol-free day/week). These 134 participants were therefore classified as hazardous or harmful drinkers. Moreover, 99 (54.7\%) reported drinking at binge levels (Over 8 units on one occasion for men and 6 for women), with 52 (28.7\%) drinking at binge levels on every drinking occasion. Consumption over the week ranged from no drinks to 90 , the mean being 13.72 (standard deviation=1.12) (Watson et al., 2006).

Conversely, substance use was reportedly lower in students who responded to the WOC questionnaire presented by Deasy et al., (2014), where 178 (11\%) were current tobacco smokers, 209 (13\%) drank alcohol more than 3 (days/week), 815 (52\%) drank alcohol more than 2 (days/week) and 104 (7\%) had used cannabis in the past 6 months.

\section{Discussion}

Being the first international systematic integrative review of PSU in midwifery populations, this article presents findings in relation to both midwives and student midwives working in three separate countries, identified from a total of three empirical studies (Deasy et al., 2014; Schluter et al., 2012; Watson et al., 2006). Substances used included tobacco, alcohol and cannabis. Problem substance use was broadly linked to longer working hours and coping with work-related stress via escape avoidance. Whilst the reasons for PSU remained unclear in the survey study by Watson et al., (2006), inferences are made by the authors that this coincided with local promotional 'Student nights', where alcohol is discounted in price.

Sources of work-related stress and psychological distress in midwifery populations can be both organisational and occupational in nature (Patterson et al., 2019; Pezaro, Sally et al., 2015). It is associated with a perceived inability to cope effectively (Ridner, 2004), in which cases midwifery populations have been known to use substances commonly, but not necessarily problematically (Dorrian et al., 2011). Alternate evidence suggests that working cultures in healthcare may actually mimic substance abuse disorder dynamics, as it can be characterised by unhealthy working patterns, often undertaken at the expense of personal relationships and self-care (Chen and Leung, 2019). Among other professional healthcare groups, drugs and alcohol have similarly been used for coping, recreational purposes, or for self-treatment of pain, anxiety, or depression (Baldisseri, 2007; Nerdrum et al., 2006; Timmins et al., 2011; Tully, 2004).

The incidence of tobacco use among students in the two included studies was reportedly $11 \%$ (Deasy et al., 2014) and 28\% (Watson et al., 2006) respectively. These figures are both lower and higher than the pooled prevalence of $21 \%$ reported in a recent systematic review and meta-analysis, representing 457,415 healthcare workers practising in 63 countries (Nilan et al., 2019). However, such data in relation to qualified midwifery populations has yet to be captured. The prevalence of participants engaged in harmful daily drinking was captured in two of the articles at both $13.9 \%$ and $74 \%$ (Schluter et al., 2012; Watson et al., 2006). This is substantially higher than the $6-10 \%$ of nurses abusing alcohol reported elsewhere (Servodidio, 2011). Cannabis use was also reportedly prevalent for $7 \%$ of the student population captured within the current review (Deasy et al., 2014). This is higher than global use of cannabis, which is currently estimated to be around 4\% (World Health Organization 
and WHO Expert Committee on Drug Dependence, 2018). Whilst it remains unclear as to the prevalence of cannabis use in midwifery populations, use of such substances among professionals and students of professional programs is not uncommon (Kiepek and Baron, 2019). Significantly, those who engage in PSU as students may be more likely to continue once they become registered professionals (Kiepek et al., 2019).

A similar review focussed upon nurses engaged in PSU identified 74 relevant articles (Ross, Berry et al., 2018). In contrast, this review, whist replicating the search strategy utilised by Ross et al., (2018) has identified only 3 relevant articles. Only one other study relating to student midwives, which briefly reports on excessive smoking, drinking or eating being used as a maladaptive coping strategy was known to the team (Davies and Coldridge, 2015). Yet this was not captured by our search strategy, presumably due to its minimal focus on PSU. Additionally, this review has solely captured PSU in relation to alcohol, tobacco and cannabis. The wider literature has demonstrated how the broader healthcare workforce engage in PSU with narcotics, opioids, benzodiazepines and/or other controlled substances (Baldisseri, 2007; Monroe, Todd and Kenaga, 2011; Smith, 2019; Srivastava, 2018). Yet due to a paucity of evidence in relation to midwifery populations, and the aggregation of midwifery professionals with those of nursing, it is unclear exactly how this particular group (midwives and student midwives) may be affected. Nevertheless, as midwifery populations also work in environments where they too may have access to controlled substances and are exposed to death and dying, the stress of which may increase the risk of drug use while practising, it is unlikely that they would not be affected in similar ways (Epstein et al., 2010; Weenink et al., 2017). Future research could usefully seek to explore and identify substance use prevalence, health risks and professional impairment in midwifery populations specifically.

The literature in relation to rehabilitation for healthcare professionals engaged in PSU remains largely dominated by outcomes for physicians (Weenink et al., 2017), of whom it is thought $8-15 \%$ are affected (Vayr et al., 2019). Generally, compassion, respect for confidentiality and a non-punitive atmosphere appear essential to recovery and the development of safer working environments, as opposed to strategies relating to discipline and stigma (Kunyk, 2015; Kunyk et al., 2016). A failure to adequately support healthcare staff engaged in PSU has been associated with organisational complicity and culpability (Searle et al., 2017). Such failures also carry significant and adverse financial implications, as well as having a detrimental impact upon any recruitment and retention strategies in place (The Royal College of Physicians, 2015). Unfortunately however, healthcare professionals may be reluctant to ask for help, or to report a colleague in need of support due to embarrassment, fear of punishment or discipline, and concerns about losing their professional license (Cares et al., 2015; Monroe, Todd and Kenaga, 2011; Pezaro, S. et al., 2016). This is of particular concern within midwifery populations, as midwives can be subjected more frequently to restrictive actions from regulators than other healthcare professionals, particularly in cases relating to drug and alcohol use (Spittal et al., 2016). Overall, the presence of unidentified substance-related impaired practice is thought to remain widespread (Kunyk, 2015). Consequently, future research could usefully explore barriers to help seeking, professional perceptions, organisational support and performance management in midwifery populations 
along with engaging in the development of evidence-based interventions designed to support them.

In terms of human cost, PSU among healthcare professionals has been implicated in medical errors and inadequate patient safety and health promotion (Bakhshi and While, 2014). Historically, it has been estimated that approximately $10 \%-15 \%$ of all health professionals have misused alcohol or drugs at some time during their careers (Baldisseri, 2007), with some developing alcohol and substance use disorders (Hasin et al., 2007; Kunyk, 2015). This is concerning, as healthcare professionals who engage in PSU have indicated that they worry about their PSU, have trouble getting along with others, provide less than their best patient care, have limited their commitment to patient care and seriously consider suicide (Kenna and Wood, 2004). Whilst it has not been possible to identify midwifery populations within such larger data sets, we concur with Weenink et al., (2017), who suggest that it is unlikely midwives are immune from such similar effects.

This review has outlined links between PSU and long working hours, work-related psychological distress and maladaptive coping via escape avoidance in midwifery populations. It is the first of its kind. There have recently been calls to explore and address such workrelated issues in health care professionals as an underrecognized threat to safe, high-quality care (Dyrbye et al., 2017; Pezaro, Sally et al., 2017; Pezaro, Sally et al., 2018). We argue that part of this strategy requires a focus on further exploring and addressing the currently under researched phenomena of midwives engaged in PSU. Of the NMC cases between 2014 and 2016 related to drug and alcohol use $n=(339)$, it is unclear precisely how many related to qualified nurses and how many related to qualified midwives (Searle et al., 2017). Equally here, we have been unable to wholly distinguish between data relating to midwifery populations and data relating to nursing and midwifery populations collectively, leaving a risk to misinterpret the specificities of PSU in midwifery populations. As such, any future research in this area could usefully collect and present contemporary data and definitions exclusively relating to the midwifery profession. 


\section{References}

Bakhshi, S., While, A., 2014. Health professionals' alcohol-related professional practices and the relationship between their personal alcohol attitudes and behavior and professional practices: a systematic review. International journal of environmental research and public health 11, 218-48.

Baldisseri, M.R., 2007. Impaired healthcare professional. Critical Care Medicine 35, S106-16.

Cares, A., Pace, E., Denious, J., Crane, L., 2015. Substance Use and Mental Illness Among Nurses: Workplace Warning Signs and Barriers to Seeking Assistance. Substance Abuse 36, 59-66.

Chen, C.A., Leung, T.I., 2019. Substance use disorders. In: Anonymous The Art and Science of Physician Wellbeing. Springer, pp. 153-177.

Davies, S., Coldridge, L., 2015. 'No Man's Land': An exploration of the traumatic experiences of student midwives in practice. Midwifery 31, 858-64.

Deasy, C., Coughlan, B., Pironom, J., Jourdan, D., Mannix-McNamara, P., 2014. Psychological Distress and Coping amongst Higher Education Students: A Mixed Method Enquiry. PLoS ONE 9, 1-23.

Dorrian, J., Paterson, J., Dawson, D., Pincombe, J., Grech, C., Rogers, A.E., 2011. Sleep, stress and compensatory behaviors in Australian nurses and midwives. Revista de saude publica 45, 922-30.

Dyrbye, L.N., Shanafelt, T.D., Sinsky, C.A., Cipriano, P.F., Bhatt, J., Ommaya, A., West, C.P., Meyers, D., 2017. Burnout among health care professionals: a call to explore and address this underrecognized threat to safe, high-quality care. NAM perspectives.

Epstein, P.M., Burns, C., Conlon, H.A., 2010. Substance abuse among registered nurses. AAOHN Journal 58, 513-6.

Folkman, S., Lazarus, R.S., 1988. Manual for the ways of coping questionnaire: Research edition. Palo Alto, CA: Consulting Psychologists 32.

Goldberg, D., 1981. Manual of the general health questionnaire (GHQ-28). Toronto: NFER NelsonPublishing (Spanish version by Masson, 1996).

Hasin, D.S., Stinson, F.S., Ogburn, E., Grant, B.F., 2007. Prevalence, correlates, disability, and comorbidity of DSM-IV alcohol abuse and dependence in the United States: results from the National Epidemiologic Survey on Alcohol and Related Conditions. Archives of General Psychiatry 64, 830-42.

Hong, Q.N., Pluye, P., Fàbregues, S., Bartlett, G., Boardman, F., Cargo, M., Dagenais, P., GagnonM-P, G.F., Nicolau, B., O'Cathain, A., 2018. Mixed methods appraisal tool (MMAT), version 2018. IC Canadian Intellectual Property Office, Industry Canada.

Hunter, B., Fenwick, J., Sidebotham, M., Henley, J., 2019. Midwives in the United Kingdom: Levels of burnout, depression, anxiety and stress and associated predictors. Midwifery 79, 102526. 
Karasek, R., Brisson, C., Kawakami, N., Houtman, I., Bongers, P., Amick, B., 1998. The Job Content Questionnaire (JCQ): an instrument for internationally comparative assessments of psychosocial job characteristics. Journal of occupational health psychology $3,322$.

Kenna, G.A., Wood, M.D., 2004. Alcohol use by healthcare professionals. Drug and alcohol dependence $75,107-16$.

Kiepek, N., Baron, J., 2019. Use of substances among professionals and students of professional programs: a review of the literature. Drugs: Education, Prevention and Policy 26, 6-31.

Kiepek, N., Harris, J., Beagan, B., Buchanan, M., 2019. Substance use by social workers and implications for professional regulation. Drugs and Alcohol Today 19, 147-59.

Koskenvuo, M., Kaprio, J., Rose, R.J., Kesäniemi, A., Sarna, S., Heikkilä, K., Langinvainio, H., 1988. Hostility as a risk factor for mortality and ischemic heart disease in men. Psychosomatic medicine.

Kunyk, D., 2015. Substance use disorders among registered nurses: prevalence, risks and perceptions in a disciplinary jurisdiction. Journal of nursing management $23,54-64$.

Kunyk, D., Inness, M., Reisdorfer, E., Morris, H., Chambers, T., 2016. Help seeking by health professionals for addiction: A mixed studies review. International journal of nursing studies 60, 20015.

Moher, D., Liberati, A., Tetzlaff, J., Altman, D.G., 2009. Preferred Reporting Items for Systematic Reviews and Meta-Analyses: The PRISMA Statement. Journal of clinical epidemiology 62, 1006-12.

Monroe, T., Kenaga, H., 2011. Don't ask don't tell: Substance abuse and addiction among nurses. Journal of Clinical Nursing 20, 504-9.

Monroe, T.B., Kenaga, H., Dietrich, M.S., Carter, M.A., Cowan, R.L., 2013. The prevalence of employed nurses identified or enrolled in substance use monitoring programs. Nursing research 62 , 10-5.

Montgomery-Dossey, B., 2009. Florence Nightingale: Mystic, Visionary, Healer.

Mumba, M.N., Kraemer, K.R., 2019. Substance Use Disorders among Nurses in Medical-Surgical, Long-Term Care, and Outpatient Services. Medsurg Nursing 28, 87-118.

Nerdrum, P., Rustøen, T., Rønnestad, M.H., 2006. Student psychological distress: a psychometric study of 1750 Norwegian 1st-year undergraduate students. Scandinavian Journal of Educational Research 50, 95-109.

Nilan, K., McKeever, T.M., McNeill, A., Raw, M., Murray, R.L., 2019. Prevalence of tobacco use in healthcare workers: A systematic review and meta-analysis. PloS one 14, e0220168.

Patterson, J., Martin, C.J.H., Karatzias, T., 2019. Disempowered midwives and traumatised women: Exploring the parallel processes of care provider interaction that contribute to women developing Post Traumatic Stress Disorder (PTSD) post childbirth. Midwifery 76, 21-35. 
Pezaro, S., Clyne, W., Fulton, E.A., 2017. A systematic mixed-methods review of interventions, outcomes and experiences for midwives and student midwives in work-related psychological distress. Midwifery.

Pezaro, S., Clyne, W., Turner, A., Fulton, E.A., Gerada, C., 2015. 'Midwives Overboard!' Inside their hearts are breaking, their makeup may be flaking but their smile still stays on. Women And Birth: Journal Of The Australian College Of Midwives 29, 59-66.

Pezaro, S., Clyne, W., Gerada, C., 2016. Confidentiality, anonymity and amnesty for midwives in distress seeking online support - Ethical? Nursing ethics.

Pezaro, S., Pearce, G., Bailey, E., 2018. Childbearing women's experiences of midwives' workplace distress: Patient and public involvement. British Journal of Midwifery 26, 659-69.

Pluye, P., Gagnon, M., Griffiths, F., Johnson-Lafleur, J., 2009. A scoring system for appraising mixed methods research, and concomitantly appraising qualitative, quantitative and mixed methods primary studies in Mixed Studies Reviews. International journal of nursing studies 46, 529-46.

Ridner, S.H., 2004. Psychological distress: concept analysis. Journal of advanced nursing 45, 536-45.

Ross, C.A., Berry, N.S., Smye, V., Goldner, E.M., 2018. A critical review of knowledge on nurses with problematic substance use: The need to move from individual blame to awareness of structural factors. Nursing inquiry 25, e12215.

Ross, C.A., Jakubec, S.L., Berry, N.S., Smye, V., 2018. "A Two Glass of Wine Shift": Dominant Discourses and the Social Organization of Nurses' Substance Use. Global Qualitative Nursing Research 5, 2333393618810655.

Roth, L.H., 1987. Chemical dependency in the health professions. Journal of nurse-midwifery 32, 917.

Schluter, P.J., Turner, C., Benefer, C., 2012. Long working hours and alcohol risk among Australian and New Zealand nurses and midwives: A cross-sectional study. International journal of nursing studies 49 , 701-9.

Searle, R., Rice, C., McConnell, A., Dawson, J., 2017. Bad apples? Bad barrels? Or bad cellars? Antecedents and processes of professional misconduct in UK Health and Social Care: Insights into sexual misconduct and dishonesty.

Servodidio, C.A., 2011. Alcohol abuse in the workplace and patient safety. Clinical journal of oncology nursing 15.

Smith, A.M., 2019. Management Strategies to Address the Substance-Impaired Healthcare Professional in the Workplace.

Spittal, M.J., Studdert, D.M., Paterson, R., Bismark, M.M., 2016. Outcomes of notifications to health practitioner boards: a retrospective cohort study. BMC medicine 14, 198.

Srivastava, A.B., 2018. Impaired Physicians: Obliterating the Stigma. American Journal of Psychiatry Residents' Journal 13, 4-6. 
The Royal College of Physicians, 2015. Work and wellbeing in the NHS: why staff health matters to patient care.

Timmins, F., Corroon, A., Byrne, G., Mooney, B., 2011. The challenge of contemporary nurse education programmes. Perceived stressors of nursing students: mental health and related lifestyle issues. Journal of psychiatric and mental health nursing $18,758-66$.

Torraco, R.J., 2005. Writing integrative literature reviews: Guidelines and examples. Human resource development review 4, 356-67.

Tully, A., 2004. Stress, sources of stress and ways of coping among psychiatric nursing students. Journal of psychiatric and mental health nursing 11, 43-7.

Vayr, F., Herin, F., Jullian, B., Soulat, J.M., Franchitto, N., 2019. Barriers to seeking help for physicians with substance use disorder: A review. Drug and alcohol dependence.

Wardle, J., Steptoe, A., 1991. The European Health and Behaviour Survey: rationale, methods and initial results from the United Kingdom. Social science \& medicine 33, 925-36.

Ware, J.E., Kosinski, M., Dewey, J.E., 2000. How to Score Version 2 of the SF-36 Health Survey (Standard \& Acute Forms). QualityMetric Incorporated.

Watson, H., Whyte, R., Schartau, E., Jamieson, E., 2006. Survey of student nurses and midwives: smoking and alcohol use. British Journal of Nursing 15, 1212-6.

Weenink, J.W., Kool, R.B., Bartels, R.H., Westert, G.P., 2017. Getting back on track: a systematic review of the outcomes of remediation and rehabilitation programmes for healthcare professionals with performance concerns. BMJ quality \& safety $26,1004-14$.

Willett, W.C., Sampson, L., Stampfer, M.J., Rosner, B., Bain, C., Witschi, J., Hennekens, C.H., Speizer, F.E., 1985. Reproducibility and validity of a semiquantitative food frequency questionnaire. American Journal of Epidemiology 122, 51-65.

World Health Organization, WHO Expert Committee on Drug Dependence, 2018. WHO Expert Committee on Drug Dependence: Fortieth Report. World Health Organization.

Worley, J., 2017. Nurses With Substance Use Disorders: Where We Are and What Needs To Be Done. Journal of psychosocial nursing and mental health services $55,11-4$. 